Çukurova Üniversitesi Mühendislik Mimarlık Fakültesi Dergisi, 35(1), ss. 19-26, Mart 2020

\title{
Farklı Atık Malzemeler ile Stabilize Edilmiş İnce Daneli Zeminin Mühendislik Özellikleri
}

\author{
Firdevs UYSAL ${ }^{* 1}$, Vedat YILMAZ ${ }^{1}$, Hüseyin Mert TOPÇU ${ }^{1}$ \\ ${ }^{1}$ Niğde Ömer Halisdemir Üniversitesi, Mühendislik Fakültesi, İnşaat Mühendisliği Bölümü, \\ Niğde
}

Geliş tarihi: 08.11.2019 Kabul tarihi: 15.05.2020

$\ddot{\mathbf{O z}}$

Dünya nüfusundaki artış endüstriyel atık malzemelerin artmasına neden olmaktadır. Endüstriyel atıkların stabilizasyonda katkı malzemesi olarak kullanımı, atıkların çevre üzerindeki olumsuz etkilerini azaltmak için kullanılan bir çözümdür. Bu çalışmanın amacı, uçucu kül, silis dumanı, yüksek fırın cürufu ve cam tozu ile stabilize edilmiş ince daneli zeminin mühendislik özelliklerini belirlemektir. İnce daneli zemin, kuru ağırlığının \%10, \%20, \%30, \%40 ve \%50 oranında atık malzeme kullanılarak stabilize edilmiştir. Deney sonuçlarına göre, yüksek firın cürufunun plastisite indisinin azaltılması ve drenajsız kayma mukavemetinin artırılmasında en etkili atık olduğu belirlenmiştir. Ayrıca, artan silis dumanı oranı ve \%20 atık oranından sonra yüksek firın cürufu ile cam tozunun lineer rötreyi azalttığı tespit edilmiştir.

Anahtar Kelimeler: Zemin stabilizasyonu, Atık malzeme, İnce daneli zemin, Mühendislik özellikler

\section{Engineering Properties of Fine-Grained Soil Stabilized with Different Waste Materials}

\begin{abstract}
The increment in world population leads to increase industrial waste materials. Utilization of industrial wastes as a stabilizing additive is a solution to reduce the negative impact of wastes on enviroment. The aim of this study is to determine variation of engineering properties of stabilized fine-grained soil with the use of fly ash, silica fume, blast furnace slag and glass dust. The soil was stabilized with using $10 \%, 20 \%$, $30 \%, 40 \%$ and $50 \%$ waste contents of weight of dry soil. Test results showed that blast furnace slag is the most effective waste in terms of reduction of the plasticity index and increasing the undrained strength of soil. Furthermore, it was observed that linear shrinkage reduced with the increase in silica fume and blast furnace slag and glass dust content with $\% 20$ above.
\end{abstract}

Keywords: Soil stabilization, Waste material, Fine-grained soil, Engineering properties

\footnotetext{
*Sorumlu yazar (Corresponding author): Firdevs UYSAL, firdevsuysal@ohu.edu.tr
} 


\section{GíRiş}

Günümüzde yaşamsal ve endüstriyel faaliyetler ile oluşan atıklar ve çevreye olumsuz etkileri kaçınılmazdır. $\mathrm{Bu}$ atık malzemelerin uzaklaştırılması ve depolanması önemli çevre problemleri yaratmaktadır. Gelişen teknolojiler ile atık ürünlerin yeniden üretime kazandırılması sağlanmakta ise de ekonomik ve kimyasal sebeplerle bir kısmı depolanmaktadır. Atık malzemelerin Batı Avrupa ve Amerika'da geri dönüşüm oran1 $\% 80$ iken, bu oran Türkiye'de \%20'dir. Bu nedenle, her y1l geri kazanilabilir malzemelerin büyük bir kısmı atık depolama sahalarına ya da çevreye gelişigüzel bırakılmaktadır. Problemli özelliklere (oturma, şişme, çökme, sıvılaşma vb.) sahip zayıf zeminlerin çeşitli katkı malzemeler ile stabilizasyonu sıkça kullanılan iyileştirme yöntemlerindendir. Atık malzemelerin zemin iyileştirilmesinde kullanımı atıkların hem ekonomiye kazandırılması hem de çevreye olabilecek zararlı etkilerinin ortadan kaldırılmasına katkı sağlayacağından birçok araştırmacının ilgisini çekmektedir [1-3]. Katk1 maddeleri olarak kireç, çimento, bitüm gibi malzemelerin yanı sıra, son yirmi yılda uçucu kül, silis dumanı, yüksek fırın cürufu, cam tozu gibi endüstriyel atıkların bu amaç için kullanımı ön plana çıkmaktadır [4-7]. Bu malzemelerden silis dumanı silisyum metali veya ferro-silisyum (FeSi) alaşımlarının üretimi sırasında kullanılan elektrik fırınlarında yüksek saflıkta kuvarsitin kömür ve odun parçacıkları ile indirgenmesi sonucu elde edilen çok ince malzemelerdir. Fırınların düşük sıcaklıklardaki üst bölümlerinde $\mathrm{SiO}$ gazı hava ile temas ederek hızla okside olur ve amorf $\mathrm{SiO}_{2}$ olarak yoğunlaşarak silis dumanı bileşiminin hemen tamamını oluşturur. Uçucu kül, kömürün tek başına termik santrallerde yakilmasi sirasinda atmosfere birakılmadan önce bacalardaki elektro filtreler sayesinde tutulan silt büyüklüğündeki malzemedir [8]. Dünyadaki enerji ihtiyacının artması ile kömür tüketimi artmaktadır ve kömür atığı olan uçucu kül miktarı da artmaktadır. Cüruf, metaller eritildiği zaman yüzeyde biriken daha hafif malzemelerdir. Atık olarak meydana çıkan bu malzemeler inşaat sektöründe çeşitli alanlarda kullanılmaktadır [9]. Cam tozu, kullanılmayan cam malzemelerden (şişe, pencere camı, vb.) oluşan atık bir malzemedir. Türkiye'de çok miktarda bulunan cam atıkları renk farklılığından dolayı geri dönüşümde çok kullanılamamaktadır [10]. Bu nedenle geri dönüştürülemeyen cam atıklarının yeniden kullanımı oldukça önemlidir [11].

Puzolanik malzemeler kendi başlarına bağlayıcılık özelliği hiç olmayan ya da oldukça az olan, ancak sulu ortamda bağlayıcılık özelliği kazanan silisli $\left(\mathrm{SiO}_{2}\right)$ ve alüminli $\left(\mathrm{Al}_{2} \mathrm{O}_{3}\right)$ malzemelerdir. Puzolan malzemeler doğal ve yapay olmak üzere ikiye ayrılırken, uçucu kül, silis dumanı, yüksek firın cürufu ve pirinç kabuğu külü gibi malzemeler yapay puzolanlar olarak adlandırılmaktadır [12].

Zeminlerin kıvamı ince daneli zeminleri tanımlayan önemli parametrelerden biri olup, mühendislik davranışı üzerinde oldukça etkilidir. Kıvamın değişimi özellikle zeminlerin dayanımı ve taşıma gücünü etkilemektedir [13]. Kohezyonlu zeminler su muhtevasının değişmesi ile büyük hacimsel değişimler gösterir ve su muhtevasının artması ile yük taşıma direnci düşerken, büyük deformasyon gösterirler. Zeminlerin hangi su muhtevasında kıvamının ne olduğunu tespit etmek ve özellikle plastik ve likit kıvamlardaki su muhtevasının bilinmesi önemlidir. Zeminlerin yüksek plastisiteye sahip olması genel olarak, şişme ve sıkışma potansiyeline sahip olduğu, su geçirgenliğinin az olduğu ve çeşitli arazi işlemlerinde (kazı ve dolgu) sorunlar yaşanabileceği anlamına gelmektedir [14]. Bu nedenle stabilizasyon çalışmalarında zeminin plastisitesinin düşürülmesi hedeflenmektedir. Zeminin rötre limiti, zeminde su kaybının daha fazla hacim değişmesine neden olmayacağ muhtevası olarak tanımlanır. Düşük rötre limitine sahip zeminlerin hacim değiştirme ihtimali yüksek olduğu için bu zeminlerde su muhtevasındaki değişimler büyük hacim değişikliklerine neden olabilir ve bu tür zeminlerde rötre oldukça büyük önem kazanır.

Bu çalışmada, sanayi atıklarından uçucu kül, silis dumanı, yüksek firın cürufu ve cam tozunun ince daneli zemin stabilizasyonundaki performans1 değerlendirilmiştir. Farklı oranlarda (\%10, \%20, $\% 30, \% 40$ ve $\% 50$ ) zemine ilave edilen atıkların 
zeminlerin kıvam limitleri, lineer rötre ve drenajsız kayma mukavemeti üzerindeki etkisi araştırılmıştır.

\section{LABORATUVAR ÇALIŞMALARI}

\subsection{Malzeme ve Zemin Özellikleri}

Bu çalışmada uçucu kül (UK), silis dumanı (SD), yüksek firın cürufu (YFC) ve cam tozu (CT) atıklarının ince daneli zemin stabilizasyonundaki performansları deneysel olarak araştırılmıştır. Çalışmanın ilk aşamasında iyileştirilen ince daneli zeminin mühendislik özellikleri tespit edilmiştir (Çizelge 1). Ayrıca, atık malzemeler temin edilerek bu atıkların kimyasal içeriği, dane dağılımı ve mikro yapısı tespit edilmiştir.

Çizelge 1. Doğal zemin özellikleri

\begin{tabular}{|l|c|}
\hline USCS sınıfı & CL \\
\hline Likit limit (\%) & 38 \\
\hline Plastik limit (\%) & 24 \\
\hline Plastisite İndisi & 14 \\
\hline Özgül ağırlık & 2.62 \\
\hline
\end{tabular}

Atık malzemelerin kimyasal içeriğinin tespiti için XRF (X-Ray Fluorescence) analizleri yapılmıştır (Çizelge 2).

Çizelge 2. Atık malzemelerin kimyasal içeriği

\begin{tabular}{|c|c|c|c|c|}
\hline & UK & SD & YFC & CT \\
\hline $\mathrm{SiO}_{2}$ & 61,252 & 93,534 & 36,824 & 71,79 \\
\hline $\mathrm{Al}_{2} \mathrm{O}_{3}$ & 22,193 & 0,778 & 13,314 & 1,04 \\
\hline $\mathrm{Fe}_{2} \mathrm{O}_{3}$ & 7,018 & 0,881 & 0,727 & 0,11 \\
\hline $\mathrm{CaO}$ & 1,472 & 0,547 & 38,834 & 9,89 \\
\hline $\mathrm{MgO}$ & 1,702 & 0,794 & 5,648 & 4,10 \\
\hline $\mathrm{K}_{2} \mathrm{O}$ & 2,335 & 0,995 & 0,777 & 0,20 \\
\hline $\mathrm{TiO}_{2}$ & 0,897 & - & 0,761 & - \\
\hline $\mathrm{SO}_{3}$ & 0,056 & 0,113 & 0,562 & 0,23 \\
\hline $\mathrm{Mn}_{3} \mathrm{O}_{4}$ & 0,068 & 0,06 & 1,17 & - \\
\hline $\mathrm{Na}_{2} \mathrm{O}$ & 0,272 & 0,404 & - & 12,41 \\
\hline $\mathrm{ZnO}_{2} \mathrm{O}$ & 0,019 & 0,012 & 0,001 & - \\
\hline $\mathrm{Cr}_{2} \mathrm{O}_{3}$ & 0,023 & 0,003 & 0,005 & - \\
\hline $\mathrm{V}_{2} \mathrm{O}_{5}$ & 0,05 & 0,002 & 0,016 & - \\
\hline $\mathrm{BaO} \mathrm{O}$ & 0,133 & - & 0,157 & - \\
\hline $\mathrm{P}_{2} \mathrm{O}_{5}$ & 0,192 & 0,088 & 0,009 & - \\
\hline
\end{tabular}

Atık malzemelerin mikro yapısının belirlenmesi için SEM (Scanning Electron Microscopy) analizleri yapılmıștır (Şekil 1). Atık malzemelerin dane dağılım eğrisi de tespit edilmiştir (Şekil 2).
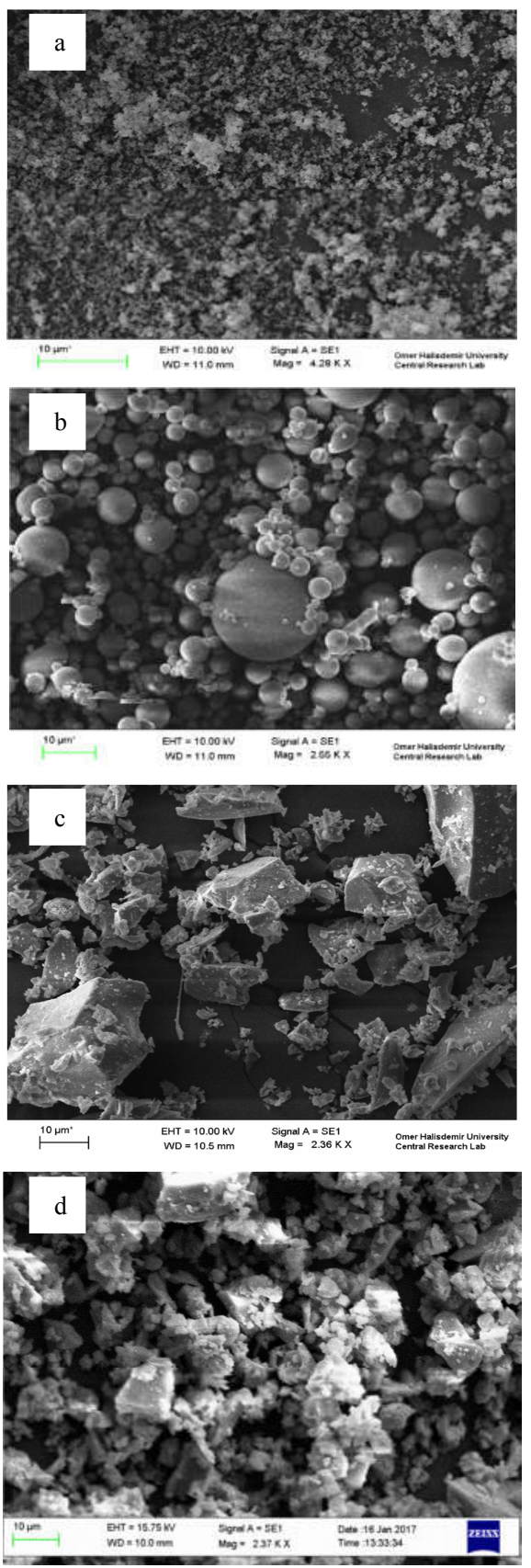

Şekil 1. SEM Görüntüleri; (a) silis dumanı (b) uçucu kül (c) yüksek firın cürufu (d) cam tozu 


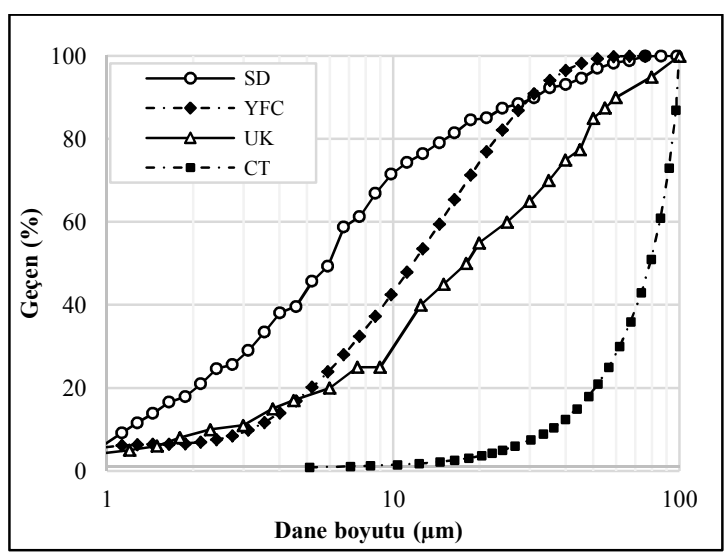

Şekil 2. Atık malzemelerin dane dağılım eğrisi

\subsection{Deneysel Çalışmalar}

Deneysel çalışmalarda dört farklı atık malzeme (UK, SD, YFC ve CT) ağırlık olarak \%10, \%20, $\% 30, \% 40$ ve $\% 50$ oranlarında ince daneli zemine karıştırılarak, atık türü ve atık oranlarının endeks ve mukavemet özellikleri üzerindeki etkisi araştırılmıştır.

Plastik limit değeri ASTM D 4318 [15] standardına uygun olarak el ile yuvarlama yöntemi ile elde edilirken, likit limit değeri de BS 1377-2 [16] standartlarına uygun olarak yarı otomatik düşen koni deneyi ile elde edilmiştir (Şekil 3). Düşen koni deneyinde $30^{\circ}$ ve 80 gram özelliğine sahip konik uç kullanılmıştır. Düşen koni deneyindeki batma miktarı ve zeminin drenajsız kayma mukavemeti arasındaki iliş̧i ilk olarak Hansbo [17] tarafindan yapılmıştır (Eşitlik 1). Ayrıca, Hansbo [17] bu çalışmada koni faktörünü (K) tanımlamıştır. Bu faktör esas olarak koni uç açısına bağlı olup, Wood [18] bu faktörü 0.85 olarak önermiştir.

$\mathrm{S}_{\mathrm{u}}=\frac{\mathrm{K} * \mathrm{Q}}{\mathrm{h}^{2}}$

$\mathrm{S}_{\mathrm{u}}=$ Drenajsız kayma mukavemeti $\left(\mathrm{kN} / \mathrm{m}^{2}\right)$

$\mathrm{K}=$ Hansbo koni faktörü

$\mathrm{Q}=$ Koni ağırlığ 1

$\mathrm{h}=$ Koni batma miktarıdır $(\mathrm{mm})$
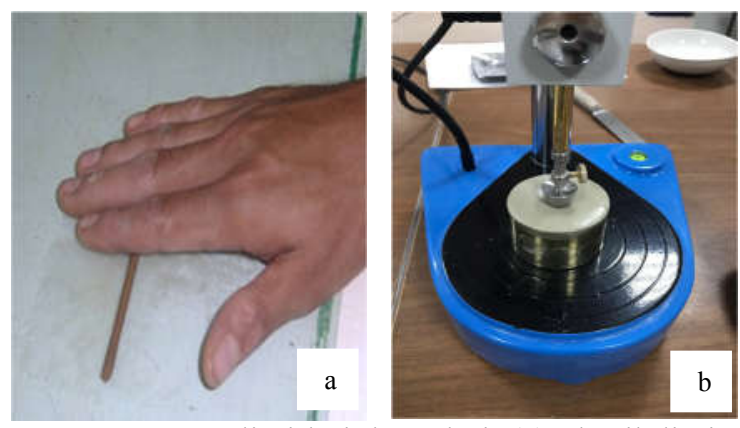

Şekil 3. Kıvam limitleri deneyleri: (a) plastik limit deneyi (b) düşen koni deneyi

Lineer rötre (tek eksenli büzülme) deneyi TS 1900-1 [19] standardına uygun olarak tüm atık oranları için tekrar edilmiştir (Şekil 4). Deneyde likit limit kıvamında hazırlanan zemin ve atık karışımı deney kalıbında yerleştirilerek, $110 \pm 5^{\circ} \mathrm{C}$ sicaklıkta 24 saat bekletilerek numunede meydana gelen boy değişimi ölçülmüştür ve tek eksenli büzülme değeri hesaplanmıştır (Eşitlik 2).

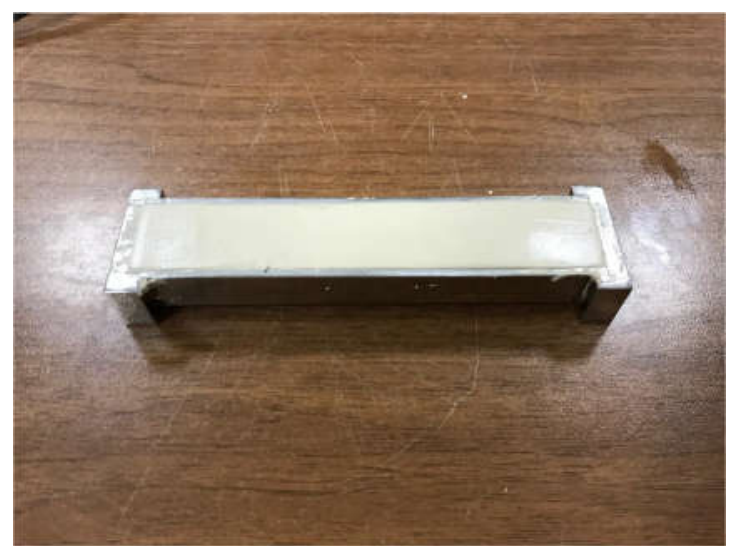

Şekil 4. Lineer rötre deneyi

$\mathrm{L}_{\mathrm{s}}=\left(1-\frac{\mathrm{L}}{\mathrm{L}_{0}}\right) 100$

$\mathrm{L}_{\mathrm{s}}=$ Tek eksenli büzülme değeri

$\mathrm{L}_{0}=$ Numunenin ilk uzunluğu

$\mathrm{L}=$ Fırında kurutulmuş numune uzunluğu

\section{DENEYSEL SONUÇLAR}

Çalışma kapsamında elde edilen laboratuvar sonuçları aşağıda sunulmaktadır. 


\section{Kıvam Limitleri Deneyleri}

Farklı atık ve atık oranları ile plastik limit, likit limit ve plastisite indisi değerleri hesaplanmış ve karşılaştırılmıştır (Şekil 5, Şekil 6 ve Şekil 7).

Artan atık oranları ile UK ve SD plastik limit değerleri azalmış, YFC değerinde artış görülürken, CT plastik limit değerinde belirgin bir değişim görülmemiştir (Şekil 5). Uçucu kül için elde edilen sonuçlar Savran [20], Amadi [21] ve Totiç [22] ile benzerdir.

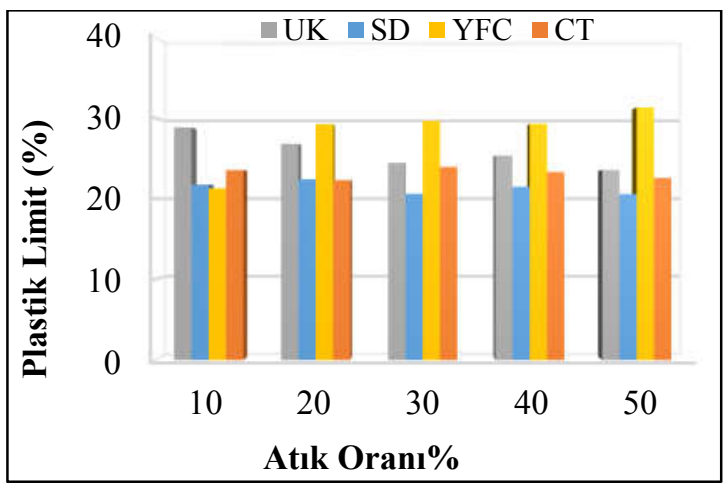

Şekil 5. Atık tür ve oranlarının plastik limite etkisi

Zemine ilave edilen artan atık oranları ile UK, CT ve SD'nin likit limitleri düşerken YFC için likit limit değerinde artışlar tespit edilmiştir (Şekil 6). Uçucu kül için elde edilen sonuçlar Yılmaz [23] ve Totiç [22] ile benzerdir. Likit limit değerindeki artışın ilk olası nedeni atık malzemelerin ilave edilmesi ile zemin danelerinin folikülasyonudur. $\mathrm{Bu}$ folikülasyon, folikül yapıdaki su tutma kapasitesini arttırmaktadır. $\mathrm{Bu}$ durum plastik limitteki değişimi de açıklamaktadır. Likit limitte meydana gelen azalma ise zemin danelerinin katyon değișimi esnasında dağınık katmanların baskılanmasından kaynaklanmaktadır [24]. Atık dane boyutu, temel olarak katyon değişimiyle kil partiküllerinin topaklanmasına neden olan bazı kimyasal reaksiyonları etkilemektedir [25]. $\mathrm{Bu}$ çalışmada kullanılan atıkların dane boyutu dağılım özellikleri birbirinden farklıdır. Kıvam limitlerindeki değişimin olası bir diğer nedeni de atıkların dane boyutu dağılımından kaynaklanmaktadır.

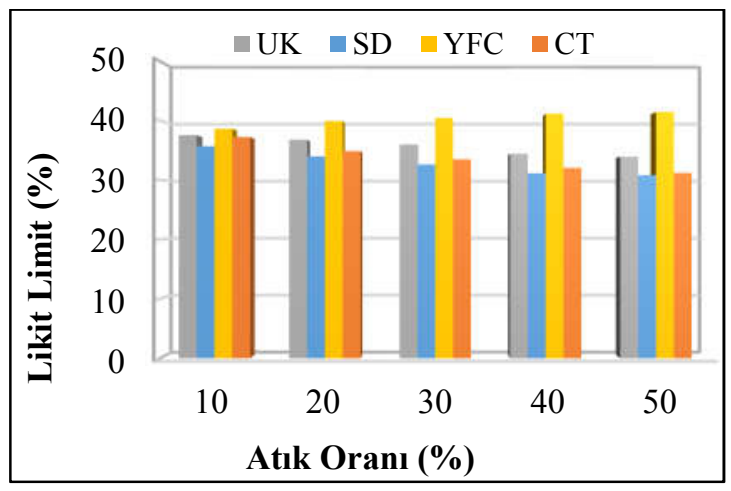

Şekil 6. Atık tür ve oranlarının likit limite etkisi

Artan atık oranları ile genel olarak CT, SD ve YFC atıklarının plastisite indisinde azalma olurken, UK için \%30 oranına kadar artış sonrasında azalma tespit edilmiştir (Şekil 7). Killi zeminlerde plastisite indisinin az olması istenen bir durumdur [26]. CT, SD ve YFC atıklarının genel trendinin plastisite indisini azaltma yönünde olduğu görülmektedir. UK atığının ise uygun oranda zemine karıştırılması ile benzer sonuçlar elde edilebilecektir. Kullanılan atıklar içinde plastisite indisini düşürmede en etkili atığın YFC olduğu tespit edilmiştir. Plastisite indisinin azalması ile de zeminin işlenebilirliği artacaktır.

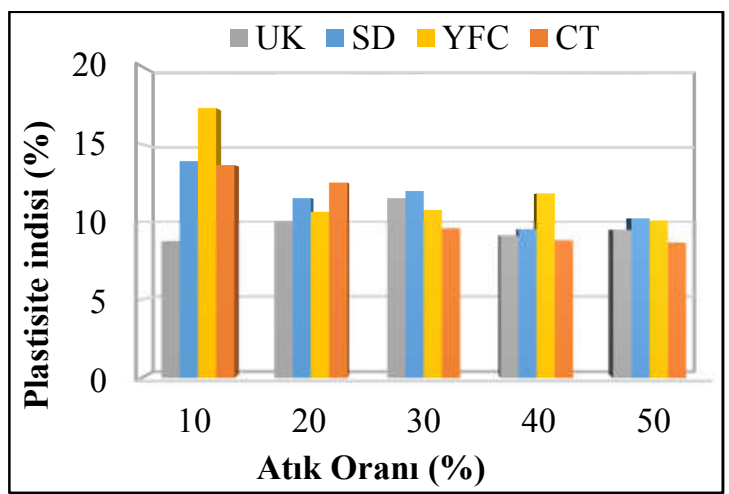

Şekil 7. Atık tür ve oranlarının plastisiteye etkisi

\section{Lineer Rötre Deneyleri}

Artan atık oranları ile SD lineer rötreyi azaltırken, bu azalma YFC ve CT için, \%20 oranından sonra gerçekleşmektedir. UK oranındaki artışlarda lineer rötrenin artmasına neden olmuştur (Şekil 8). Bose [27], artan UK miktarı rötre limitinin \%3 oranında 
artarken, lineer rötrenin de azaldığını tespit etmiştir.

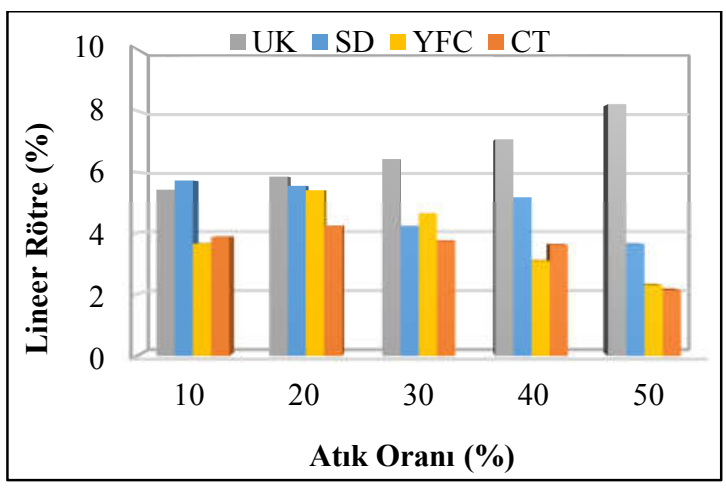

Şekil 8. Atık tür ve oranlarının lineer rötreye etkisi

\section{Drenajsı, Kayma Mukavemetinin Tespiti}

Tüm atık tür ve oranları \%40 su muhtevası ile hazırlanarak düşen koni deneyleri yapılmış ve bu su içeriğindeki batma miktarları tespit edilmiştir. Hansbo [17] bağıntısı ile drenajsız kayma mukavemeti değerleri hesaplanarak karşılaştırılmıştır.

Artan atık oranları ile UK ve SD atıklarının drenajsı kayma mukavemetlerinde azalma görülürken, YFC ve CT'de ise artışlar meydana gelmiştir (Şekil 9).

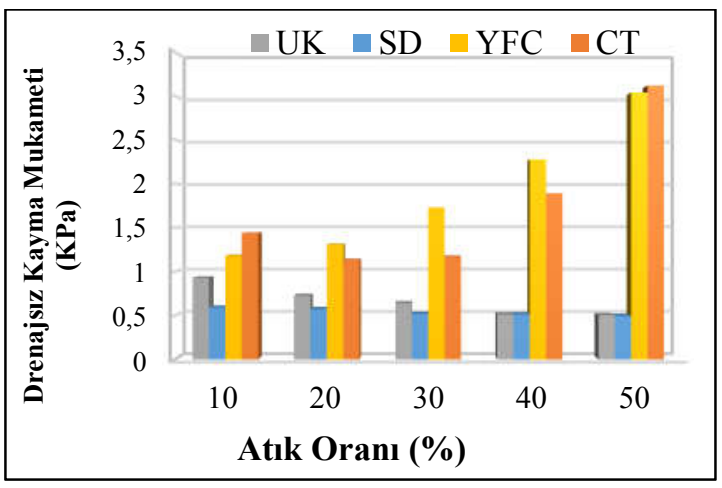

Şekil 9. Atık tür ve oranlarının anlık mukavemete etkisi

En belirgin mukavemet artışı YFC'de tespit edilmiştir. Çetin [12] UK için optimum karışım oranının \%10 olduğunu bundan daha fazla UK oranlarında drenajsiz kayma mukavemetinde düşmelerin olduğunu belirtmiştir. Tumluer [28], cüruf katkısı ile hazırlanan numune dayanımının zamana bağlı olarak artış göstereceğini belirtmiştir. Aksoy ve arkadaşları [29], puzolanik özellikli malzeme dayanımındaki artışın genellikle 90 günde belirginleştiğini ifade etmiştir. Puzolanik etkinin de göz önünde alınmasıyla, bu çalışma kapsamında yapılan anlık dayanımların zamana bağlı olarak artış gösterebileceği düşünülmektedir.

\section{SONUÇLAR}

Çalışma kapsamında kullanılan UK, SD, YFC ve CT atıklarının değișen oranlarla ince daneli zemine ilave edilmesi ile zeminin kıvam, lineer rötre ve drenajsız kayma mukavemeti özelliklerindeki değişim araştırılmıştır. Elde edilen sonuçlar aşağıda özetlenmiştir.

- Artan atık oranları ile UK ve SD atıkları plastik limiti azaltırken, YFC atığı plastik limiti arttırmış ve CT atığı ise plastik limit değerinde belirgin bir değişime neden olmamıştır.

- Artan UK, CT ve SD oranları ile zeminin likit limiti azalırken, YFC likit limiti arttırmaktadır.

- Artan atık oranları ile genel olarak CT, SD ve YFC atıkları plastisite indisini azaltmıştır. UK atığında ise $\% 30$ oranına kadar plastisite indisinde artış olurken, sonrasında azalma tespit edilmiştir.

- Plastisite indisinin azaltılmasında en etkili atığın YFC olduğu tespit edilmiştir. Plastisite indisinin azaltılması da zeminin işlenebilirliğini arttıracaktır.

- SD oranının artması ile lineer rötre azalırken, YFC ve CT atıkları için \%20 oranından sonra azalma gerçekleşmektedir. UK atığının artması ise lineer rötrenin artmasına neden olmuştur.

- Artan atık oranları ile UK ve SD drenajsız kayma mukavemetinde azalmaya neden olurken, YFC ve CT mukavemette artış1 sağlamıştır. En belirgin mukavemet artışı YFC atığında tespit edilmiştir. 


\section{KAYNAKLAR}

1. Achmad, F., Nazmi, W.M., Fauzi U.J., 2011. California Bearing Ratio (CBR) Improvement of Kuantan Clay Subgrade By Using Reused Material as Stabilizer. 9th National Conference of the Indonesia Road Development Association (IRDA), Jakarta.

2. Abd EI-Aziz, M.A., Abo-Hashema, M.A., 2013. Measured Effects on Engineering Properties of Clayey Subgrade using LimeHomra Stabiliser. International Journal of Pavement Engineering, 14-4, 321-332.

3. James, J., Pandian P.K., 2018. Bagasse Ash as an Auxiliary Additive to Lime Stabilization of an Expansive Soil. Strength and Microstructural Investigation. Advances in Civil Engineering.

4. Senol, A., Edil, T.B., Bin-Shafique M.S, Acosta, H.A., Benson C.H., 2006. Soft Subgrades Stabilization by Using Various Fly Ashes. Resources, Conservation Recycling, 46(4), 365-376.

5. Singh, P.S., Yadav, R.K., 2014. Effect of Marble Dust on Index Properties of Black Cotton Soil. International Journal of Scientific Research Engineering \& Technology, 158-163.

6. Saygili, A., 2015. Use of Waste Marble Dust for Stabilization of Clayey Soil. Materials Science, 21(4), 601-606.

7. Öncü, Ş., Bilsel, H., 2018. Utilization of Waste Marble to Enhance Volume Change and Strength Characteristics of Sand-Stabilized Expansive Soil. Environmental Earth Sciences, 77(12), 461.

8. Malhotra, V.M., Carette, G.C., Sivassundaram, V., 1994. Role of Silica Fume in Concrete a Review, Advances in Concrete Technology, Canmet, Ottwa, 925-991.

9. Ünal, O., Güçlüer, K., 2016. Gazbeton Üretiminde Yüksek Fırın Cürufu Kullanılabilirliğinin Araştırılması, Afyon Kocatepe Üniversitesi Fen ve Mühendislik Bilimleri Dergisi, Özel Sayı, 218-221.

10. Topcu, I.B., Canbaz, M., 2004. Properties of Concrete Containing Waste Glass Cem. Concr. Res, 34, 267-274.
11. Turgu, P., 2008. Limestone Dust and Glass Powder Wastes as New Brick Material. Materials and Structures, 41(5), 805-813.

12. Çetin, A.Y., 2011. Yüksek Plastisiteli Kil Zeminlerin Alternatif Malzemeler ile Yüzeysel Zemin Stabilizasyonu, Yüksek Lisans Tezi, Fen Bilimleri Enstitüsü, İstanbul Teknik Üniversitesi.

13. Y1lmaz, L, 2002. Killi Zeminlerde Kivam Limitleri ve Kompaksiyon Parametrelerinin Is1 ile Değişimi. Yüksek Lisans Tezi. Atatürk Üniversitesi Fen Bilimleri Enstitüsü, s.78, Erzurum.

14. Palalı, A, 2006. Handere Kilinde Su İçeriği Değişimi ve Kompaksiyon Enerjisinin Mukavemete Olan Etkisi. Yüksek Lisans Tezi. Çukurova Üniversitesi Fen Bilimleri Enstitüsü, s.98, Adana.

15. ASTM D 4318 2013. Standard Test Methods for Liquid Limit, Plastic Limit, and Plasticity İndex of Soils. West Conshohocken, PA, USA.

16. BS 1377-2 1990. Methods of Test for Soils for Civil Engineering Purposes. Part 2, Classification Tests, BSI.

17. Hansbo, S., 1957. A New Approach to the Determination of the Shear Strengh of Clay by the Fall-Cone Test, Royal Swedish Geoteknical Institute, Linköping, Sweden, s.7-47.

18. Wood, D.M., 1985. Some Fallcone Tests. Geotech 35(1), 64-68.

19. TS 1900-1 2006. İnşaat Mühendisliğinde Zemin Laboratuar Deneyleri-Bölüm 1: Fiziksel Özelliklerin Tayini. Türk Standartları Enstitüsü, Ankara.

20. Savran, K.Z., 1988. Stabilization of Cohesive Soils With Fly Ash, Orta Doğu Teknik Üniversitesi, Yüksek Lisans Tezi, s.62, Ankara.

21. Amadi, A., 2010. Evaluation of Changes in Index Properties of Lateritic Soil Stabilized With Fly Ash. Leonardo Electronic Journal of Practices and Technologies, 9(17), 69-78.

22. Totiç, E., Göktepe, F., Yaşar, M., 2019. Uçucu Kül Katkısının Killi Zeminlerin Mekanik Özelliklerine Etkisi. Dicle Üniversitesi Mühendislik Fakültesi Mühendislik Dergisi, 10(2), 769-778.

23. Y1lmaz, F., 2016. Zemin Stabilizasyonunda Uçucu Kül Kullanımı, ISEM2016, $3^{\text {rd }}$ 
International Symposium on Environment and Morality, 4-6 November 2016, Alanya-Turkey.

24.Umesha, T.S., Dinesh, S.V., Sivapullaiah, P.V., 2009. Control of Dispersivity of Soil Using Lime and Cement. International Journal of Geology, 3(1), 8-16.

25. Ji-ru, Z., Xing, C., 2002. Stabilization of Expansive Soil by Lime and Fly Ash. Journal of Wuhan University of Technology-Mater. Sci. Ed., 17(4), 73-77.

26. Sivapullaiah, P.V., Sridharan, A., Bhaskar, R.K.V., 2000. Role of Amount and Type of Clay in the Lime Stabilization of Soils. Ground Improv., 4, 37- 45.

27. Bose, B., 2012. Geo Engineering Properties of Expansive Soil Stabilized with Fly Ash. Electronic Journal of Geotechnical Engineering, 17(1), 1339-1353.

28. Tumluer, G., 2006. Çimento Katkılı Kumlu Zeminlerin Mukavemeti. Çukurova Üniversitesi Fen Bilimleri Enstitüsü Yüksek Lisans Tezi, s.161, Adana.

29. Aksoy, H.S., Yılmaz, M., Akarsu, E.E., 2008. Killi Bir Zeminin Tunçbilek Uçucu Külü Kullanılarak Stabilizasyonu. Frrat Üniversitesi Doğu Araştırmaları Dergisi, 6(3), 88-92. 